Article

\title{
The Emulsifying Properties of Hydrogenated Rosin Xylitol Ester as a Biomass Surfactant for Food: Effect of $\mathrm{pH}$ and Salts
}

\author{
Hong Qiu ${ }^{1}$, Xiaopeng Chen ${ }^{1,2}$, Xiaojie Wei ${ }^{1,2}$, Jiezhen Liang ${ }^{1,2}$, Dan Zhou ${ }^{1}$ and \\ Linlin Wang ${ }^{1,2, *}$ \\ 1 School of Chemistry and Chemical Engineering, Guangxi University, Nanning 530004, China; \\ qiuhong@mail.gxu.cn (H.Q.); lilm@gxu.edu.cn (X.C.); wxjgxu@gxu.edu.cn (X.W.); ljztonyol@163.com (J.L.); \\ 1814404054@st.gxu.edu.cn (D.Z.) \\ 2 Guangxi Key Laboratory of Petrochemical Resources Processing and Process Intensification Technology, \\ Guangxi University, Nanning 53004, China \\ * Correspondence: wanglinlin1971@163.com; Tel.: +86-771-3272702
}

Received: 25 November 2019; Accepted: 8 January 2020; Published: 12 January 2020

\begin{abstract}
The xylitol ester of hydrogenated rosin (XEHR) was obtained for the first time from biomass-based hydrogenated rosin and xylitol using an environmentally friendly, high-pressure $\mathrm{CO}_{2}$ catalytic synthesis. This compound is intended for use as an emulsifier for food. Analyses by ICP-AES showed the absence of heavy metal residues in the product, such that it met food standards. Fourier transform infrared and nuclear magnetic resonance spectroscopies together with gel permeation chromatography confirmed the successful esterification and the formation of a monoester and diester with molar masses of 427 and $772 \mathrm{~g} / \mathrm{mol}$. The emulsification of water/soybean oil mixtures by adding the $\mathrm{XEHR}$ was assessed at $\mathrm{pH}$ values of 4, 6.86, and 10 and in the presence of $\mathrm{NaCl}, \mathrm{KCl}, \mathrm{MgCl}_{2}$, and $\mathrm{CaCl}_{2}$. The XEHR was found to act as an emulsifier by reducing the interfacial tension of such mixtures to less than $2 \mathrm{mN} / \mathrm{m}$ under all conditions. The highest emulsifying activity index $\left(9.52 \mathrm{~m}^{2} / \mathrm{g}\right)$ and emulsifying stability index $(94.53 \%)$ were obtained after adding $\mathrm{MgCl}_{2}(100 \mathrm{mM})$. Particle size and confocal microscopy showed that the presence of salts gave a more uniform droplet size and a finer emulsion structure. The high viscosities of the emulsions containing salts also suggested a more cohesive oil droplet network.
\end{abstract}

Keywords: xylitol ester of hydrogenated rosin; emulsifying properties; water-in-oil emulsions; $\mathrm{pH}$; salts

\section{Introduction}

An emulsifier is a type of surfactant capable of rapidly reducing the interfacial tension between oil and water [1]. These compounds are important ingredients in forming stable emulsions with suitable shelf-lives and functional properties [2], and they are widely used in foods [3], cosmetics [4] and catalysis [5], and as templates for the preparation of advanced materials [6]. Emulsifiers employed in the food industry come from a wide range of sources, including milk (or whey), eggs, soybeans, soluble polysaccharides, pectin, and gum arabic [7]. The emulsifying properties of such materials are attributed to the specific carbohydrates or proteins that they contain [8]. At present, there are few commercial applications for artificial emulsifiers because these are synthesized using toxic solvents and thus can contain residues of such toxins [9]. In contrast, emulsifiers modified by the addition of proteins are widely used because of their high nutritional value [10] and excellent functional characteristics [11]. However, some studies have shown that these proteins may act as common food allergens. There are also rising concerns related to dietary restrictions associated with milk and egg proteins, the spread of 
diseases such as bovine spongiform encephalitis, and multidrug-resistant food-borne pathogens [12]. In addition, because these emulsifiers exhibit different properties depending on the acidity/basicity or salt content of their environment [13], it is challenging to expand their applications.

The manufacturers of emulsion products must understand the behavior of these surfactants under different conditions, such as over a wide $\mathrm{pH}$ range or in the presence of salts, so as to select the most suitable surfactants for specific applications. For all these reasons, it would be of interest to develop environmentally friendly methods of synthesizing stable emulsifiers and to study the emulsion behavior of these compounds under different conditions.

Rosin is a nonvolatile solid obtained from living pine trees and comprises a mixture of resin acids having different molecular structures [14]. As a natural renewable resource, rosin is both inexpensive and abundant, with an annual production worldwide of approximately 1.2 million tons [15]. Hydrogenated rosin is one of the main products obtained from this material because it has the advantages of a light color, oxidation resistance, and minimal brittleness [16]. In addition, the conjugated double bonds in rosin can be hydrogenated while retaining the hydrophobic nature of the tricyclic phenanthrene skeleton and the carboxyl groups. Thus, hydrogenated rosin can be used as a raw material for the synthesis of surfactants $[17,18]$. In recent years, biomass-based food additives have been synthesized from hydrogenated rosin because this represents a "green" raw material [19]. As an example, the well-known hydrogenated rosin glyceride, which can be used as an emulsifier and density modifier in nonalcoholic drinks and turbid drinks, has been listed as a food additive in the United States, Japan, Spain, and China [20,21]. However, the carboxyl group in hydrogenated rosin is connected with the tertiary carbon atom, having a strong steric effect, which makes the reaction activation energy of the carboxyl group high. Thus, research concerning the hydrogenated rosin esterification process of hydrogenated rosin not only focuses on improving technical performance but also on the design of clean synthetic routes. As a means of providing an environmentally friendly reaction medium for chemical synthesis, high-pressure $\mathrm{CO}_{2}$ can be used to replace traditional solvents [22]. In recent years, many research studies have shown that pressurized $\mathrm{CO}_{2}$ can be used as a "green" reaction medium, in particular for catalysis.

Xylitol, a five-carbon sugar alcohol, is a naturally occurring polyalcohol [23]. Because this compound is highly water soluble, it has been widely used in various food products, such as sugar-free gum and baking products [24]. Xylitol does not need insulin to participate in the metabolism of the body, and it does not increase the blood sugar value; therefore, the nutritive sweetener xylitol is being considered as a possible alternative for glucose and sucrose in the diet of diabetic patients [25]. At the same time, xylitol has some special physiological functions such as preventing caries, eliminating blood ketone disease, and improving liver function [26]. Xylitol fatty acid esters can also act as surfactants [27]. Moreover, sugar-based fatty acid esters are commercially used as emulsifiers in foods at concentrations as high as $10 \mathrm{mg} / \mathrm{mL}$, which reflects their low toxicities. The maximum daily intake for these materials is also quite high at $20 \mathrm{mg} / \mathrm{kg}$ body weight [28].

In this work, the xylitol ester of hydrogenated rosin (XEHR) was synthesized for the first time, using xylitol as the hydrophilic portion of the molecule and hydrogenated rosin as the hydrophobic portion, in conjunction with high-pressure $\mathrm{CO}_{2}$ (Figure 1). The objectives of this investigation were to characterize the chemical structure and physical properties of XEHR as a chemically synthesized emulsifier, as well as to determine the surface activity of this molecule and the properties of soybean oil/water/XEHR emulsions. The emulsions were evaluated while varying both $\mathrm{pH}$ and salt type, and rheometry, particle size analysis, and microscopy were used to explore the relationship between the emulsion microstructure and the emulsifying properties of the XEHR. The raw materials used in this experiment were obtained from biomass (a renewable feedstock), the synthetic method was environmentally friendly, and the product was found to have a stable chemical structure. It is expected that XEHR may have a number of applications in acidic, basic, or high-salt emulsion systems. 


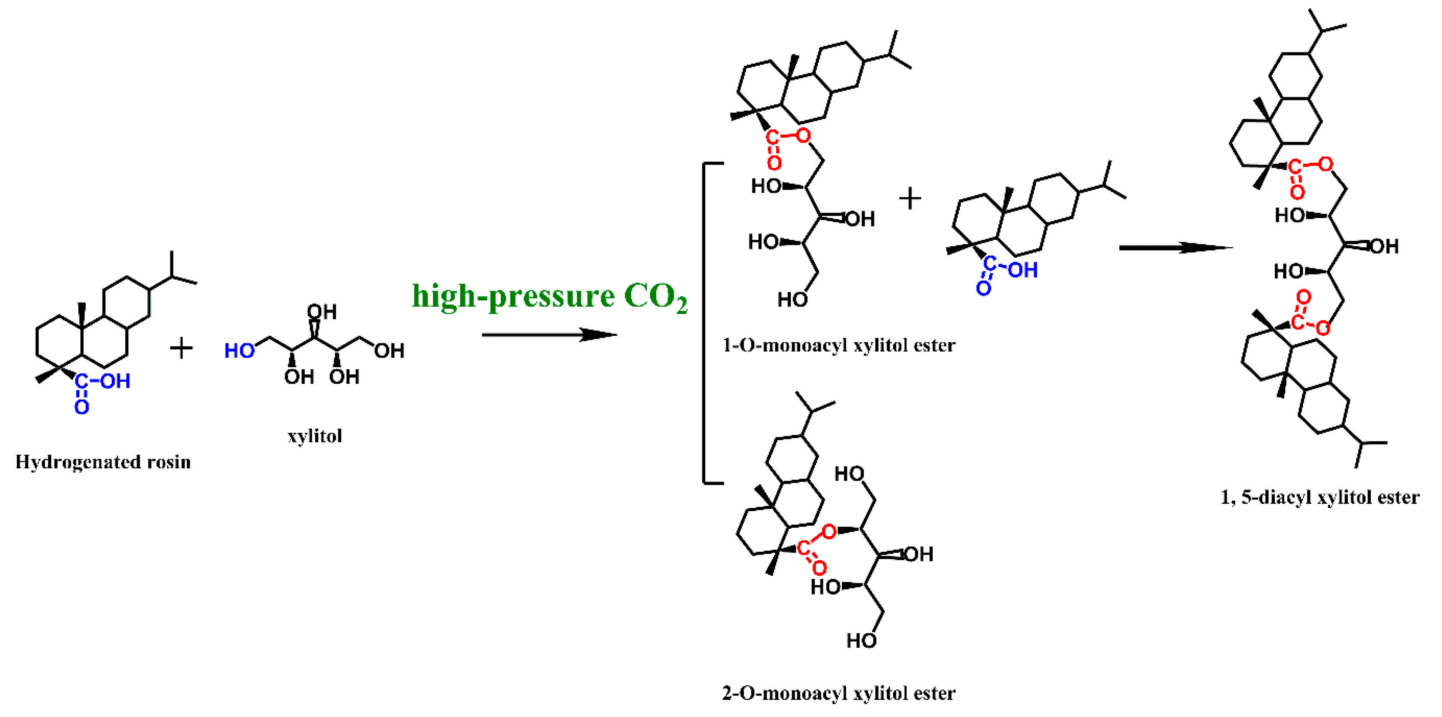

Figure 1. Reaction network diagram of hydrogenated rosin and xylitol.

\section{Results and Discussion}

\subsection{Preparation}

\subsubsection{Conversion Values}

In this work, esterification was carried out under various conditions, and the relevant results are shown in Figure 2. The initial conditions of this experiment were as follows: temperature, $220^{\circ} \mathrm{C}$; reaction time, $1 \mathrm{~h}$. As there is no relevant report on the production of rosin xylitol ester, according to the existing ASTM D-465 standard [29], the conversion value of rosin ester must be greater than $90 \%$. Without any catalyst, the esterification rate was only $16.70 \%$ after one hour. When $1 \mathrm{MPa} \mathrm{CO}_{2}$ was filled into the reaction system, the esterification rate rose to $25.95 \%$ after one hour. When the $\mathrm{CO}_{2}$ pressure in the system rose from 1 to $4 \mathrm{MPa}$, the conversion rate increased from $25.95 \%$ to $37.02 \%$, but when the $\mathrm{CO}_{2}$ pressure changed from 4 to $5 \mathrm{MPa}$, the conversion rate did not change significantly. It shows that $4 \mathrm{MPa} \mathrm{CO}_{2}$ has reached the catalytic saturation. Considering the cost, the following experiments were carried out at $4 \mathrm{MPa}$. At the same time, because significant activation energy is needed for esterification, it is very important to choose the reaction temperature. When the temperature increased from 220 to $250{ }^{\circ} \mathrm{C}$, the conversion increased from $37.02 \%$ to $59.07 \%$. When the reaction temperature increased from 250 to $260^{\circ} \mathrm{C}$, the conversion increase was very limited, and the color of the product deepened. First of all, the activation energy of esterification can be reached by increasing the temperature, but the $\mathrm{pH}$ of the reaction system will also increase with the increase of temperature, which reduces the catalytic effect of $\mathrm{CO}_{2}$, and the resin acid will cause cracking at high temperature. Because there are multiple competing reactions in the system, the reaction temperature was determined as $250^{\circ} \mathrm{C}$. Next, the effect of reaction time was studied. When the reaction time was extended from 1 to $4 \mathrm{~h}$, the conversion was over $90 \%$. As the esterification reaction is reversible and has a reaction limit, the effect of prolonging the reaction time on the conversion rate was not obvious after $4 \mathrm{~h}$. Finally, the best reaction conditions were determined: temperature, $250{ }^{\circ} \mathrm{C} ; \mathrm{CO}_{2}$ pressure, $4 \mathrm{MPa}$; time, $4 \mathrm{~h}$. 

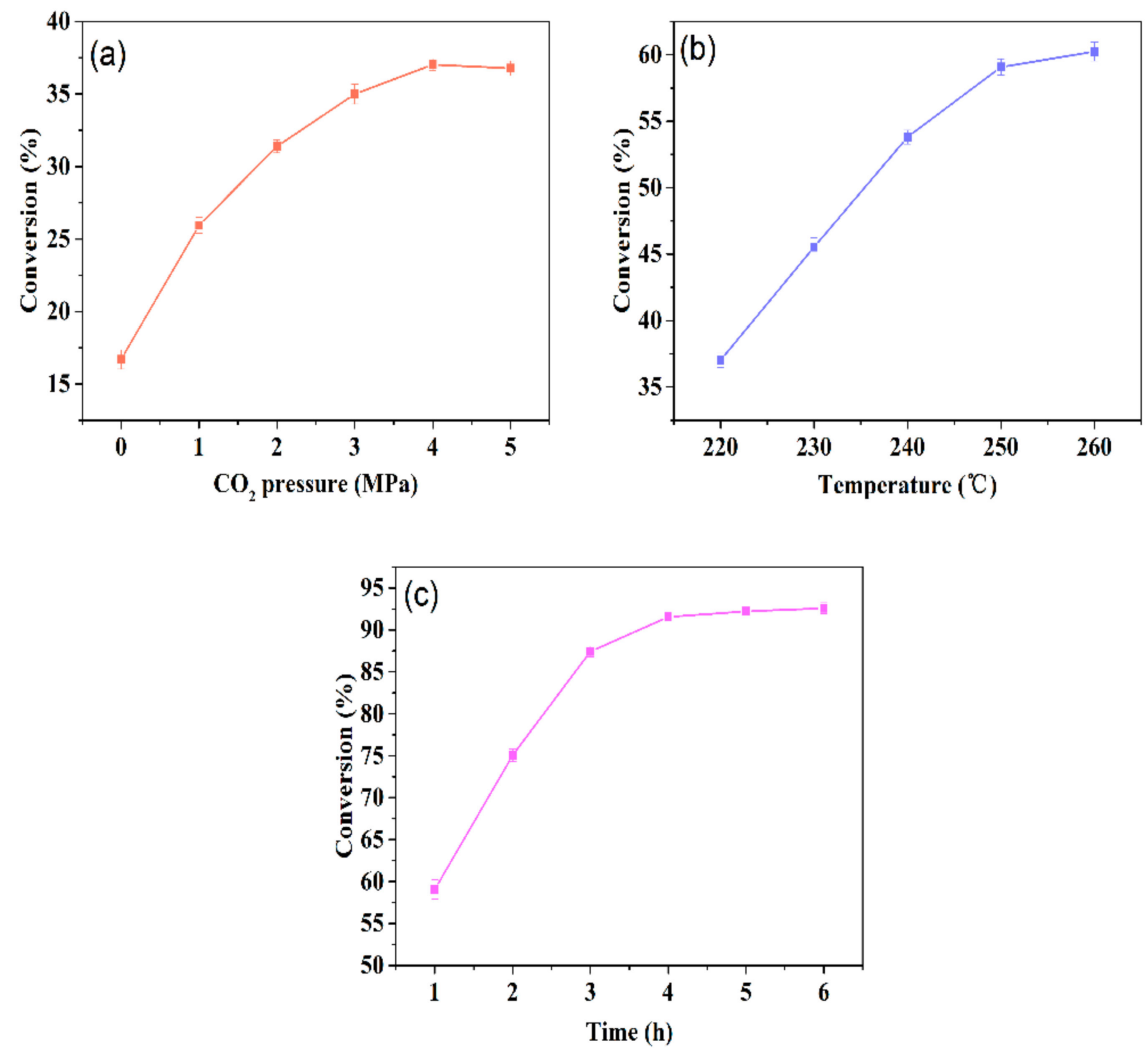

Figure 2. Hydrogenated rosin conversion versus various reaction conditions. Reaction conditions: stirring speed, $400 \mathrm{r} / \mathrm{min}$; the molar ratio of hydrogenated rosin to xylitol, 1:1. (a) Temperature, $220^{\circ} \mathrm{C}$; time, 1 h. (b) Pressure of $\mathrm{CO}_{2}, 4 \mathrm{PMa}$; time, $1 \mathrm{~h}$. (c) Pressure of $\mathrm{CO}_{2}, 4 \mathrm{PMa}$; temperature, $250{ }^{\circ} \mathrm{C}$.

Finally, the esterification experiments were carried out under three conditions with the optimal reaction conditions above: (1) with no catalyst, (2) with the traditional $\mathrm{ZnO}$ catalyst $(0.8 \%)$, and (3) with high-pressure $\mathrm{CO}_{2}$ as the catalyst $(4 \mathrm{MPa})$, and the associated esterification rates were ascertained. As shown in Table 1, only partial esterification was obtained without the catalyst, and the conversion rate of the hydrogenated rosin was unsatisfactory. Using the $\mathrm{ZnO}$, the conversion percentage was increased to $78.52 \%$, but the required conversion rate of $90 \%$ within $4 \mathrm{~h}$ was not obtained. In contrast, $91.51 \%$ conversion was obtained after $4 \mathrm{~h}$ with the high-pressure $\mathrm{CO}_{2}$ catalysis. These data confirm that high-pressure $\mathrm{CO}_{2}$ exhibits superior catalytic activity during esterification.

Table 1. Esterification conversion values under different catalytic conditions. Reaction conditions: (1) no catalyst, (2) the traditional $\mathrm{ZnO}$ catalyst $(0.8 \%)$, (3) high-pressure $\mathrm{CO}_{2}$ as the catalyst $(4 \mathrm{MPa})$. Common reaction conditions: temperature $=250{ }^{\circ} \mathrm{C}$, time $=4 \mathrm{~h}$, molar ratio of hydrogenated rosin to xylitol $=1: 1$.

\begin{tabular}{cc}
\hline Samples & Conversion (\%) \\
\hline XEHR (without catalyst) & $63.65 \pm 0.05^{\mathrm{c}}$ \\
XEHR (ZnO as catalyst) & $78.52 \pm 0.06^{\mathrm{b}}$ \\
\hline XEHR (high-pressure $\mathrm{CO}_{2}$ as catalyst) & $91.54 \pm 0.03^{\mathrm{a}}$
\end{tabular}

Values are given as the mean $\pm \mathrm{SD}$ from triplicate determinations; ${ }^{\mathrm{a}-\mathrm{c}}$ indicates that different letters in the same column differ significantly $(p<0.05)$; XEHR, xylitol ester of hydrogenated rosin.

\subsubsection{Hydrophilic-Lipophilic Balance (HLB) Value}

Emulsifiers having low HLB values tend to be oil soluble, and materials having high values tend to be water soluble. Calculation of HLB values of surfactant is very important in product quality 
and yield points of view [30]. There are many kinds of rosin derivatives as surfactants [31], which have different applications according to their HLB values. For example, rosin glyceride mentioned in the introduction, will generally be mixed with other surfactants or used as emulsifier after further modification (such as the reported rosin-based polymer, prepared by the establishment of rosin with glycol and pentaerythritol [32]). When pentaerythritol was mixed additionally, the HLB value can reach 9.92, which can be used as a cream base. The reported rosin imides maleic anhydride adduct is a surfactant that can be used in organic solvents [33]. A kind of polymer of coconut oil, rosin, and maleic anhydrides, whose HLB value can reach 13.82, can be used in making liquid, powder, and cake detergent [34]. The HLB values determined for the XEHR are presented in Figure 3. The average HLB value for the three groups of samples was 7.81, which falls within the range of suitable values for the preparation of oil in water emulsions.

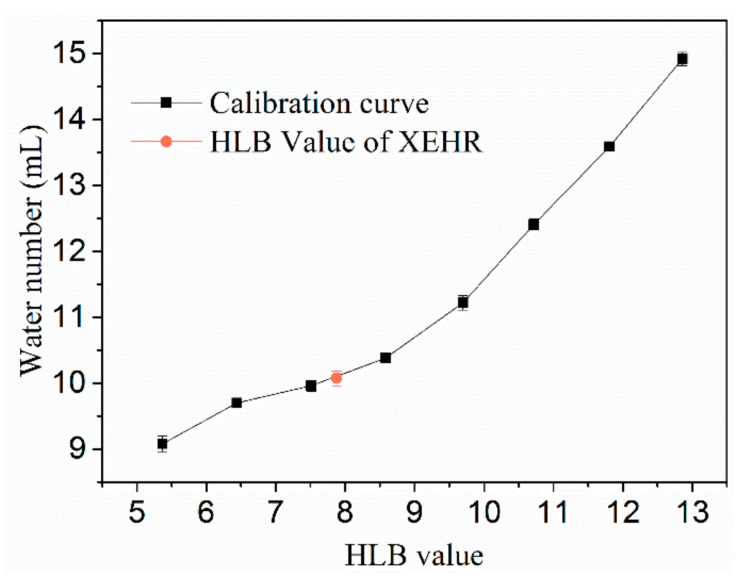

Figure 3. The hydrophilic-lipophilic balance (HLB) calibration curve (based on Greenwald et al.) and the HLB values for the XEHR. The plot of water number vs. HLB was obtained from Equation (2) using span- 80 and tween-80 mixtures.

\subsubsection{ICP-AES}

Compared with the product synthesized using $\mathrm{ZnO}$, the $\mathrm{Zn}$ concentration in the product obtained using high-pressure $\mathrm{CO}_{2}$ was much lower, and it was approximately equal to that in the hydrogenated rosin (Table 2). The $\mathrm{Zn}$ in the hydrogenated rosin and the increase in the trace $\mathrm{Zn}$ level in the sample after the reaction are attributed to contamination from the raw material packaging and residues from the reactor. The $\mathrm{Cu}, \mathrm{Fe}, \mathrm{Ni}$, and $\mathrm{Pb}$ concentrations in the XEHR met the requirements for use of this material as a food additive according to U.S. Food and Drug Administration standards [29].

Table 2. $\mathrm{Cu}, \mathrm{Fe}, \mathrm{Pb}, \mathrm{Zn}$, and Ni concentrations in the hydrogenated rosin (row 1), XEHR generated by $\mathrm{ZnO}$ catalysis (row 2), and XEHR generated by high-pressure $\mathrm{CO}_{2}$ catalysis (row 3 ) as determined by ICP-AES.

\begin{tabular}{cccccc}
\hline Samples & $\mathbf{C u}(\mathbf{\%})$ & Fe (\%) & Ni (\%) & Pb (\%) & Zn (\%) \\
\hline Hydrogenated rosin & $<0.0004$ & $<0.0004$ & $<0.0004$ & $<0.0004$ & 0.0013 \\
\hline XEHR (ZnO as catalyst) & $<0.0004$ & $<0.0004$ & $<0.0004$ & $<0.0004$ & 0.20 \\
\hline XEHR (high-pressure $\mathrm{CO}_{2}$ as catalyst) & $<0.0004$ & $<0.0004$ & $<0.0004$ & $<0.0004$ & 0.0018 \\
\hline
\end{tabular}

\subsection{Characterization}

\subsubsection{FTIR}

FT-IR spectra of the XEHR and hydrogenated rosin can be found in the Supplementary Materials (see Figure S1). In the spectrum obtained from the hydrogenated rosin, the peak at $1276 \mathrm{~cm}^{-1}$ is 
attributed to the stretching vibration of the carboxylic acid C-O bond, while that at $1695 \mathrm{~cm}^{-1}$ results from the stretching vibration of the $\mathrm{C}=\mathrm{O}$ bond in the same moiety. Following the reaction with xylitol, the peak associated with the $\mathrm{C}-\mathrm{O}$ bond is shifted to $1242 \mathrm{~cm}^{-1}$, indicating the $\mathrm{C}-\mathrm{O}-\mathrm{C}$ stretching vibration of an ester group. In addition, the $\mathrm{C}=\mathrm{O}$ peak is moved to $1727 \mathrm{~cm}^{-1}$, confirming that the hydrogenated rosin was converted to XEHR. The intense, broad peak at $3443 \mathrm{~cm}^{-1}$ is characteristic of the stretching vibration of the $\mathrm{O}-\mathrm{H}$ bonds in xylitol. These results demonstrate a higher degree of esterification in the product [35].

\subsubsection{NMR}

${ }^{1} \mathrm{H}$ and ${ }^{13} \mathrm{C}$ NMR spectra can be found in the Supplementary Materials (see Figure S1). Here, a chemical shift, $\delta\left({ }^{13} \mathrm{C}\right)$, of $178.51 \mathrm{ppm}$ is ascribed to the ester group, while the peaks at 4.01, 4.04, and $3.74 \mathrm{ppm}\left({ }^{1} \mathrm{H}\right)$ and $65.44,65.44$, and $69.46 \mathrm{ppm}\left({ }^{13} \mathrm{C}\right)$ are ascribed to the 1-O-monoacyl xylitol ester. The small peaks at $4.88 \mathrm{ppm}\left({ }^{1} \mathrm{H}\right)$ and $75.26 \mathrm{ppm}\left({ }^{13} \mathrm{C}\right)$ are due to the $\mathrm{H} 2 / \mathrm{C} 2$ atoms of the 2-O-monoacyl xylitol ester. In addition, the peaks at $3.73 \mathrm{ppm}\left({ }^{1} \mathrm{H}\right)$ and $68.88 \mathrm{ppm}\left({ }^{13} \mathrm{C}\right)$ correspond to the methyl group in the 1,5-diacyl xylitol ester. Therefore, the hydrogenated rosin and xylitol evidently formed two esters in the reaction process. No evidence for a triacyl xylitol ester was found, which may partly be due to steric hindrance [36-38].

\subsubsection{GPC}

The GPC data obtained from analysis of the raw hydrogenated rosin and of the reaction mixture after $4 \mathrm{~h}$ are provided in Figure 4, while the molecular weights and molecular weight distributions are summarized in Table 3. These results verify the presence of mono- and diesters in the samples. The raw rosin produced a single peak at a retention time of $10.184 \mathrm{~min}$, equivalent to an $\mathrm{Mr}$ of 276, demonstrating that the raw material contained only the resin acid. After $4 \mathrm{~h}$ of reaction, two peaks appeared at 9.618 and $9.887 \mathrm{~min}$, corresponding to $\mathrm{Mr}$ values of 772 and 427, respectively. These are consistent with the respective molecular weights of the diacyl and monoacyl xylitol esters and, thus, are consistent with the NMR results. Notably, the peak associated with the diacyl xylitol ester was the largest. Thus, during the $4 \mathrm{~h}$ reaction, the rosin not only reacted with the xylitol to form a significant quantity of the monoester, but it also continued to react to produce the diester. The polydispersity index for each of these peaks was close to 1 , indicating that there were almost no side reactions.
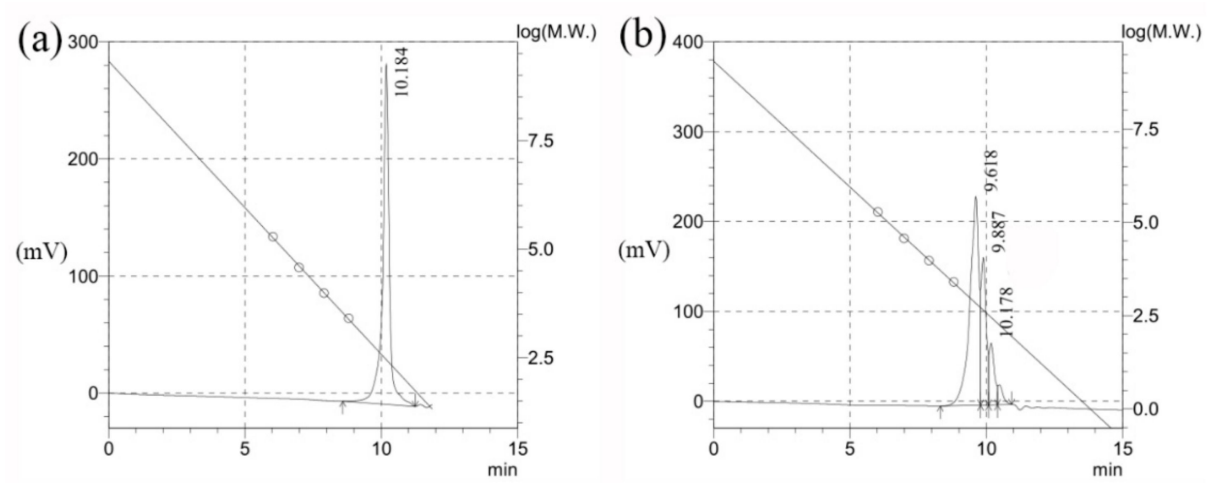

Figure 4. GPC chromatograms and calibration curves for (a) the hydrogenated rosin and (b) the XEHR.

Table 3. GPC data for the hydrogenated rosin and XEHR.

\begin{tabular}{cccc}
\hline Retention Time (min) & Mn & Mw & Polydispersion Index \\
\hline 10.184 & 276 & 319 & 1.15367 \\
9.618 & 772 & 844 & 1.09319 \\
9.887 & 427 & 433 & 1.01454 \\
10.178 & 266 & 271 & 1.01699 \\
\hline
\end{tabular}




\subsection{Emulsification Properties}

\subsubsection{Surface and Interfacial Tensions}

The interfacial tension at a liquid-liquid interface is a crucial factor related to the study and characterization of emulsion stability. As an example, the introduction of surfactant molecules prevents the coalescence of oil droplets by reducing the interfacial tension of the mixture [39]. The surface tension curve for soybean oil containing XEHR is shown in Figure 5a, and the critical micelle concentration (CMC) value can be determined from the inflection point of this plot. It can be seen from these data that the XEHR had only a limited effect in terms of reducing the surface tension of pure soybean oil. This is attributed to the lower surface tension of the soybean oil itself and the irregular arrangement of surfactant molecules on the surface of the oil [40]. However, when water is added, the hydrophilic head of the XEHR molecule positions itself in the aqueous phase while the hydrophobic tail extends into the oil phase, such that the interfacial tension between the soybean oil and water is greatly reduced. Figure $5 b-d$ illustrates the effects of $\mathrm{pH}$, salt concentration, and salt type on the interfacial tension. It can be seen from the figure that, in general, XEHR had a good ability to reduce the interfacial tension in different $\mathrm{pH}$ and salt environments. However, the ability of XEHR to reduce the interfacial tension under acidic conditions was slightly weaker than that in neutral and alkaline environments. The reason is that different $\mathrm{pH}$ values may lead to changeable intra- and intermolecular repulsions of XEHR, which neutralizes the surface charge of XEHR and reduces the surface potential of particles [41]. Because the molecular weight of the hydrophobic group in XEHR is larger, XEHR is more lipophilic, especially when the charge is almost lost, and it is easy to be trapped in the oil [8]. However, since XEHR is not a polyelectrolyte, the effect of $\mathrm{pH}$ on its interfacial properties is finite. As shown in Figure $5 \mathrm{c}$, when 10 $\mathrm{mm} \mathrm{NaCl}$ is contained in the aqueous solution, the interfacial tension slightly increased at the same concentration of XEHR, compared with that in the neutral environment, but with the increase of salt concentration, XEHR gradually showed a better ability to reduce the interfacial tension. According to the report, the presence of cations (e.g., $\mathrm{Ca}^{2+}$ and $\mathrm{Na}^{+}$) may shield the negative charges of surfactant movements, thus decreasing the repulsive force between drops [40]. At the same time, $\mathrm{NaCl}$ was beneficial to promote surface movements to transfer from the bulk solution to oil-water interface, compress the electrical double layer, and form a compact surfactant molecule arrangement on the interfacial layer [42]. Because of the interaction of the two effects, the interfacial tension increased first and then decreased with the increase of salt concentration. In other kinds of salt solutions, it also showed low interfacial tension (Figure 5d), especially in $\mathrm{NaCl}$ and $\mathrm{MgCl}_{2}$. Under these conditions, the surface tension was decreased below $2 \mathrm{mN} / \mathrm{m}$, and the interfacial properties were better than those reportedly obtained from other artificial emulsifiers [6]. These results confirm that the XEHR is capable of forming effective emulsions. 

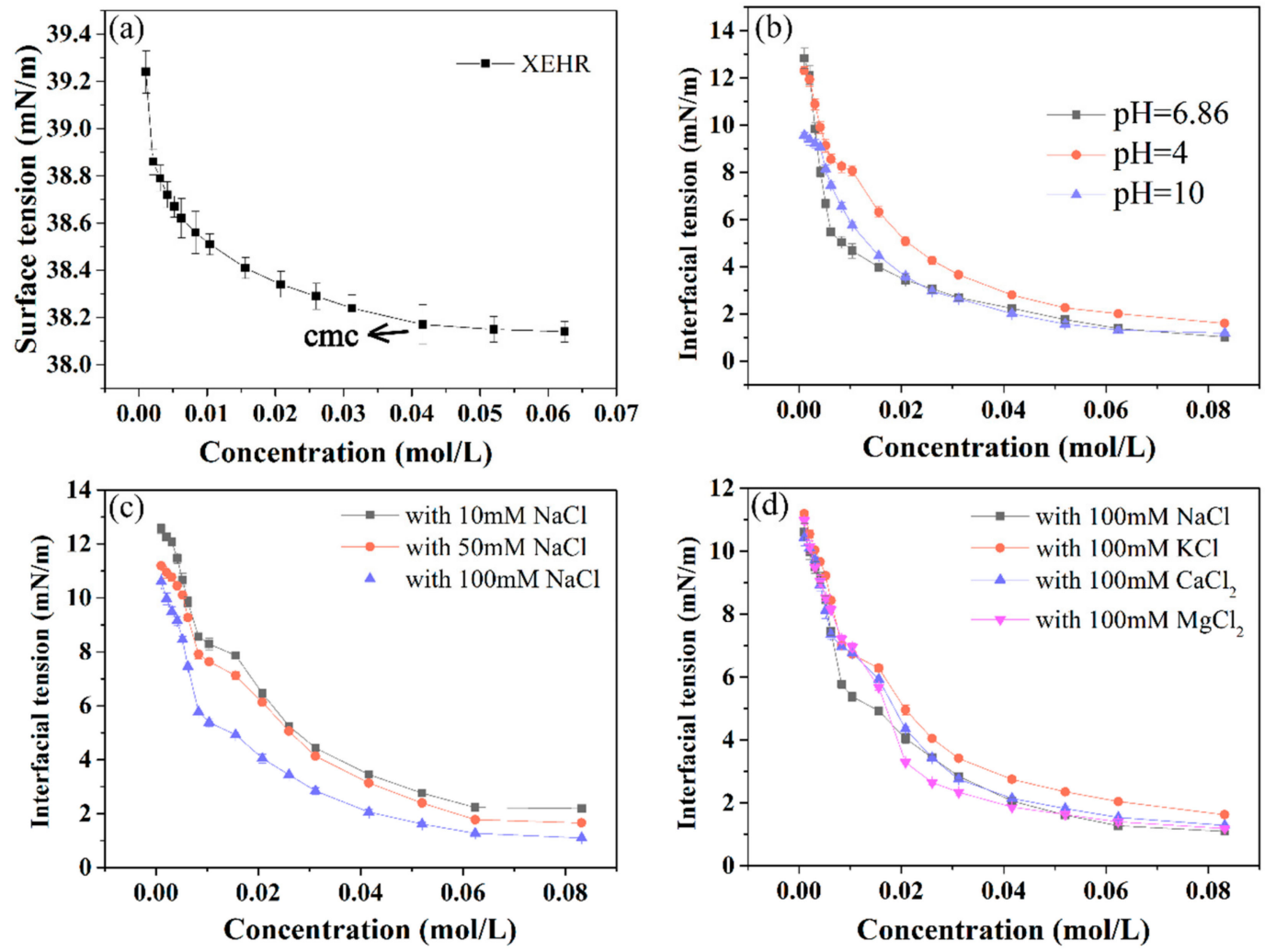

Figure 5. The surface tension curves for (a) XEHR in pure soybean oil, and for XEHR in oil/soybean mixtures showing the effects of (b) $\mathrm{pH}$, (c) salt concentration, and (d) salt type.

\subsubsection{Emulsifying Activity}

The emulsifying activity index (EAI) is an indicator of formation ability of an emulsion, while the emulsifying stability index (ESI) reflects the ability of an emulsion to maintain stability. Table 4 shows the emulsification performance of the XEHR under different conditions. The emulsifying activity without the XEHR was low, such that the emulsion was uneven and relatively unstable. The EAI values of the XEHR emulsions were also found to increase in neutral or alkaline environments. The lowest EAI of $7.11 \mathrm{~m}^{2} / \mathrm{g}$ appeared at a $\mathrm{pH}$ of 4 , with an ESI of 75.56, showing that the emulsion stability was poor in acidic environments. In contrast to the majority of modified protein surfactants, the XEHR emulsions containing high salt concentrations exhibited higher EAI values, and the ESI also increased with increases in the $\mathrm{NaCl}$ concentration. The highest EAI appeared in the emulsions containing 100 $\mathrm{mM} \mathrm{NaCl}$ or $\mathrm{MgCl}_{2}$, while the stabilities of emulsions containing $\mathrm{MgCl}_{2}$ and $\mathrm{KCl}$ were slightly higher than those for emulsions made with $\mathrm{NaCl}$ or $\mathrm{CaCl}_{2}$. These data are in good agreement with previous reports of the effects of inorganic salts such as $\mathrm{NaCl}, \mathrm{KCl}$, and $\mathrm{CaCl}_{2}$ on emulsion stability, and they demonstrate that the stability of some emulsions increase with increases in salt concentration [43]. The reason may be that, after the emulsion formed by XEHR, the droplets in the oil phase are equivalent to many micro interfaces. The surface charge of the droplet is not zero, and the droplets are kept stable by electrostatic exclusion. Just as electrostatic interaction can neutralize interfacial charges and make XEHR far away from the interface, the change of $\mathrm{pH}$ also weakens the electrostatic repulsion between droplets, resulting in flocculation and in low stability of emulsion in acidic environments [44], but this effect is not significant. Similarly, as salt affects the interfacial tension of soybean oil/water with XEHR, the stability of emulsion in salty environments also showed the same rule as that of interfacial tension tests. Overall, the XEHR showed a similar emulsifying activity to that reported for protein-based emulsifiers [45], which indicates that XEHR has the potential to replace protein-based emulsifiers in the food industry [46]. The emulsification behavior primarily depends on the stability of the surfactant 
structure and molecular flexibility [47]. Thus, bio-based surfactants that are highly readily adsorbed at the oil-water interface will produce better emulsification activity and stability.

Table 4. Emulsifying activity index (EAI) and emulsifying stability index (ESI) values for emulsions made with the XEHR with different $\mathrm{pH}$, salt concentrations, and salt species.

\begin{tabular}{ccc}
\hline Samples & $\begin{array}{c}\text { Emulsifying Activity } \\
\text { Index }\left(\mathbf{m}^{2} / \mathbf{g}\right)\end{array}$ & $\begin{array}{c}\text { Emulsifying Stability } \\
\text { Index (\%) }\end{array}$ \\
\hline Emulsion without XEHR & $4.60 \pm 0.31^{\mathrm{g}}$ & $70.0 \pm 0.64 \mathrm{~g}$ \\
$\mathrm{pH}=6.86$ & $7.94 \pm 0.09^{\mathrm{c}}$ & $84.69 \pm 0.38^{\mathrm{bc}}$ \\
$\mathrm{pH}=4$ & $7.11 \pm 0.11^{\mathrm{f}}$ & $75.56 \pm 1.57^{\mathrm{ef}}$ \\
$\mathrm{pH}=10$ & $7.92 \pm 0.18^{\mathrm{cd}}$ & $82.65 \pm 1.28^{\mathrm{cd}}$ \\
$10 \mathrm{mM} \mathrm{NaCl}$ & $7.33 \pm 0.35^{\text {ef }}$ & $72.71 \pm 0.70^{\mathrm{f}}$ \\
$50 \mathrm{mM} \mathrm{NaCl}$ & $7.64 \pm 0.39^{\mathrm{de}}$ & $78.56 \pm 1.75^{\mathrm{de}}$ \\
$100 \mathrm{mM} \mathrm{NaCl}$ & $9.33 \pm 0.20^{\mathrm{a}}$ & $84.36 \pm 0.29^{\mathrm{bc}}$ \\
$100 \mathrm{mM} \mathrm{KCl}$ & $8.37 \pm 0.33^{\mathrm{bc}}$ & $89.26 \pm 3.08^{\mathrm{ab}}$ \\
$100 \mathrm{mM} \mathrm{MgCl}_{2}$ & $9.52 \pm 0.13^{\mathrm{a}}$ & $94.53 \pm 1.53^{\mathrm{a}}$ \\
$100 \mathrm{mM} \mathrm{CaCl}_{2}$ & $8.75 \pm 0.13^{\mathrm{b}}$ & $80.20 \pm 1.12^{\mathrm{cd}}$ \\
\hline
\end{tabular}

Values are given as the mean \pm SD from triplicate determinations; ${ }^{a-g}$ indicates that different letters in the same column differ significantly $(p<0.05)$.

\subsubsection{Microstructures of Emulsions}

The particle sizes and optical micrographs of emulsion samples made under different conditions are provided in Figures 6 and 7, respectively. The emulsion without the XEHR was evidently uneven and unstable and showed large, irregular droplets with sizes between 10 and $20 \mu \mathrm{m}$. After adding the XEHR, the droplet sizes decreased to 6 to $10 \mu \mathrm{m}$ under acidic conditions, and these droplets were relatively uniform in size and shape. Under alkaline and neutral conditions, smaller droplets (2 to $4 \mu \mathrm{m}$ ) appeared in the emulsions. The average droplet size in the $100 \mathrm{mM} \mathrm{MgCl} 2$ emulsion was the smallest $(3$ to $7 \mu \mathrm{m})$, and the droplet morphology was more uniform. The droplet sizes were 1.5 to 3 $\mu \mathrm{m}$ and 6 to $10 \mu \mathrm{m}$ in the emulsion containing $\mathrm{CaCl}_{2}$, indicating both large and small droplets. The particle sizes in the emulsion containing $\mathrm{NaCl}$ were between 4 and $10 \mu \mathrm{m}$, with few variations in shape. The particle sizes in the $\mathrm{KCl}$ emulsion were the largest among the various salt emulsions (5 to $10 \mu \mathrm{m}$ ), with the majority of droplets having a size of approximately $8 \mu \mathrm{m}$. The effect of salt on the droplet size is attributed to the effect of charge screening [48] and cationic gelling agent [42]. The larger the viscosity of the continuous phase in the emulsion, the smaller the droplet agglomeration tendency, and the smaller the particle size, the more evenly dispersed it is in the emulsion network structure [45], which means that the stability of the emulsion is stronger. This can also be confirmed by comparing the experimental results of emulsion size and emulsion stability.

Zeta potentials also provide useful information regarding the stability of an emulsion (Table 5). It is reported that a higher zeta potential value is accompanied by a more stable emulsion. Generally, an absolute zeta potential value of $25-30 \mathrm{mV}$ is typically used as an approximate threshold for stability [49]. The zeta potential of the emulsion without the XEHR was less than $20 \mathrm{mV}$, indicating an unstable mixture. The zeta potentials of the acidic emulsions were also found to be positive and small. It can be seen that in neutral and saline environments, the surface charge of the droplet was negative. Only when $\mathrm{pH}=4$ was applied did the Zeta potential become positive and the absolute value decrease. This proves that the acidic environment will neutralize and change the negative charge on the surface of the droplet, which may be the reason why the emulsion was slightly less stable under acidic conditions. The zeta potentials of the emulsions containing salts were higher than those without salts at all $\mathrm{pH}$ values. The highest zeta potential was obtained using $\mathrm{MgCl}_{2}(-41.75 \mathrm{mV})$, indicating that this was the most stable emulsion. The Zeta potential test results coincide very well with the ESI and other test results. Therefore, this experiment has proved the high stability of XEHR salt-containing emulsion from many aspects and its good emulsifying properties under various environmental conditions. 

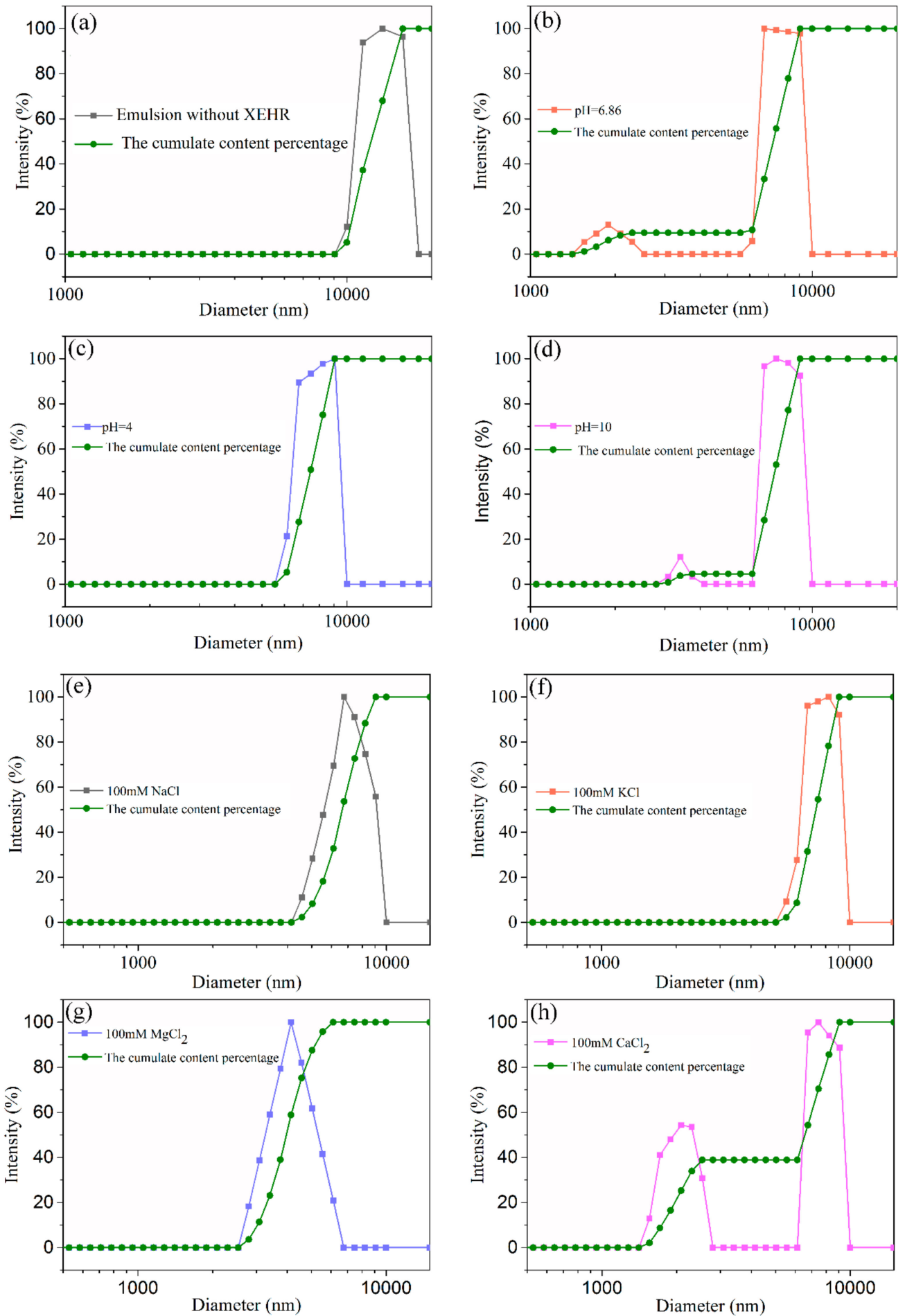

Figure 6. The particle size distribution curves and cumulative content percentage curves of emulsions under different $\mathrm{pH}$ and different salt conditions. (a) Emulsion without the $\mathrm{XEHR}$, (b) emulsion $\mathrm{pH}=$ 6.86, (c) emulsion $\mathrm{pH}=4$, (d) emulsion $\mathrm{pH}=10$, (e) emulsion containing $\mathrm{NaCl} 100 \mathrm{mM}$, (f) emulsion containing $\mathrm{KCl} 100 \mathrm{mM}$, (g) emulsion containing $\mathrm{MgCl}_{2} 100 \mathrm{mM}$, (h) emulsion containing $\mathrm{CaCl}_{2}$ $100 \mathrm{mM}$. 


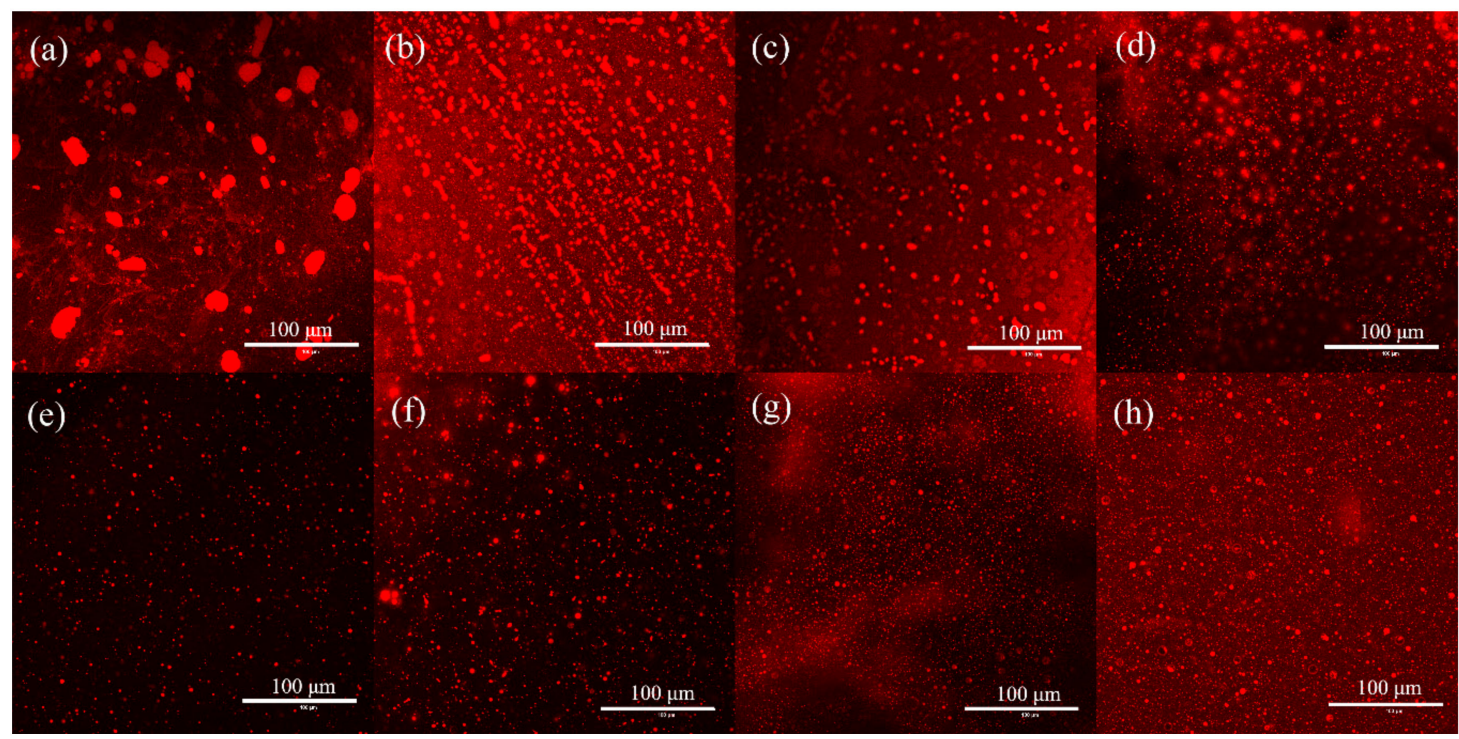

Figure 7. The microstructures of emulsions (a) without the XEHR, and at $\mathrm{pH}$ of (b) 6.86, (c) 4, and (d) 10, and with (e) $100 \mathrm{mM} \mathrm{NaCl}$, (f) $100 \mathrm{mM} \mathrm{KCl,} \mathrm{(g)} 100 \mathrm{mM} \mathrm{MgCl}_{2}$, and (h) $100 \mathrm{mM} \mathrm{CaCl}_{2}$. The scale bars indicate $100 \mu \mathrm{m}$.

Table 5. Zeta potentials of emulsion samples under different conditions.

\begin{tabular}{|c|c|c|c|}
\hline Samples & Zeta Potentials (mV) & Samples & Zeta Potentials (mV) \\
\hline Emulsion without XEHR & $-16.41 \pm 3.09^{c}$ & $100 \mathrm{mM} \mathrm{NaCl}$ & $-37.58 \pm 1.01^{a}$ \\
\hline $\mathrm{pH}=6.86$ & $-35.72 \pm 2.42^{d}$ & $100 \mathrm{mM} \mathrm{KCl}$ & $-39.45 \pm 5.36^{d}$ \\
\hline $\mathrm{pH}=4$ & $27.88 \pm 1.41^{b}$ & $100 \mathrm{mM} \mathrm{MgCl}_{2}$ & $-41.75 \pm 4.72^{\mathrm{d}}$ \\
\hline $\mathrm{pH}=10$ & $-37.51 \pm 5.29 d$ & $100 \mathrm{mM} \mathrm{CaCl}_{2}$ & $-32.61 \pm 3.26^{\mathrm{ab}}$ \\
\hline
\end{tabular}

Values are given as the mean \pm SD from triplicate determinations; ${ }^{\text {a-d }}$ indicates that different letters in the same column differ significantly $(p<0.05)$.

\subsubsection{Emulsion Rheology}

To better understand the relationship between emulsion structure and macroscopically measurable properties, rheology tests were carried out to ascertain the relationship between the internal structure and flow characteristics. The apparent viscosity of an emulsion plays a key role in the formation and stability of the mixture. Specifically, increases in viscosity inhibit the free movement of the two phases as well as phase separation and flocculation. The viscosity changes of the emulsions at various shear rates and with different $\mathrm{pH}$ environments and salt types are presented in Figure 8. After XEHR addition, the viscosity of the emulsion decreased sharply with increases in shear rate, thus showing shear thinning behavior. The viscosity of emulsion was obviously the lowest when XEHR was not added. After adding XEHR, the viscosity of the emulsion increased in all $\mathrm{pH}$ environments. The appearance of non-Newtonian shear thinning was most evident in the case of the mixtures incorporating salts, which showed higher viscosities in the range of 20 to $70 \mathrm{~Pa} \cdot \mathrm{s}$. This result is in agreement with the increased ESI values of the salt-based emulsions (Table 4). These data suggest that these emulsions had stronger oil droplet networks with smaller average droplet sizes. Studies have shown that the addition of substances that are not adsorbed in the emulsion can increase the viscosity of the aqueous phase and limit the movement of droplets, thus improving the stability of the emulsion [50]. 

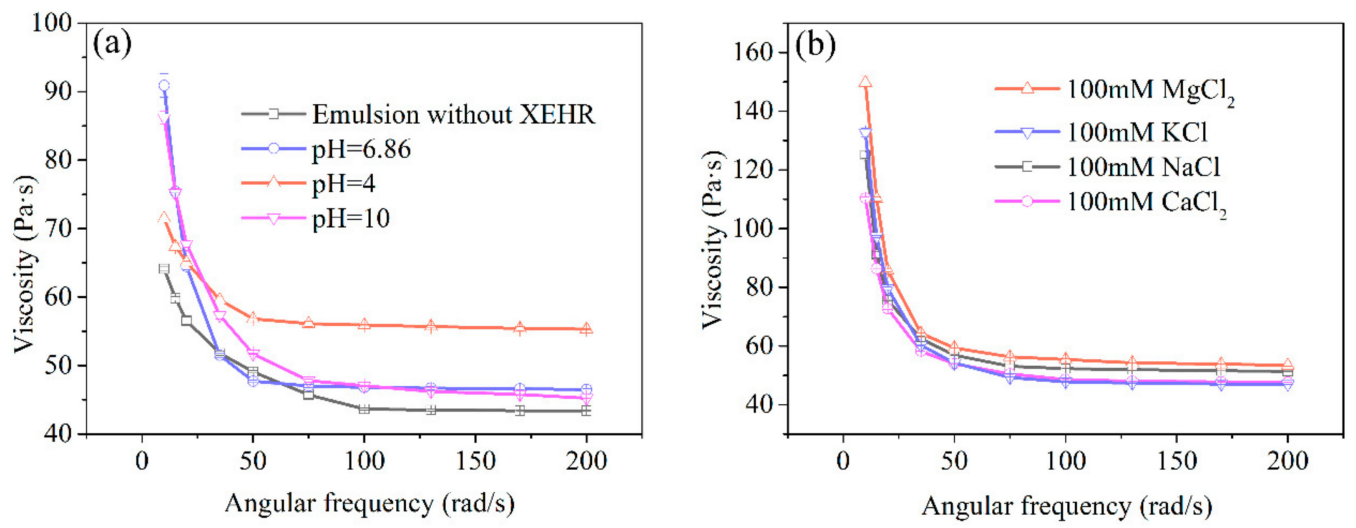

Figure 8. The viscosities of emulsions (a) without the XEHR and at different $\mathrm{pH}$ (b) containing various salts.

\section{Materials and Methods}

\subsection{Materials}

Hydrogenated rosin (N grade, composed of approximately 95\% colophony acids, acid value 191.79 $\mathrm{mg} \mathrm{KOH} / \mathrm{g}$ ) was acquired from Guangxi Wuzhou Pine Chemicals (Guangxi, China). First-class soybean oil was purchased in a local supermarket. Rhodamine B was obtained from the Damao Chemical Reagent Factory (Tianjin, China). Food-Grade xylitol was obtained from the Futaste Pharmaceutical Co., Ltd. (Shandong, China). Carbon dioxide (99.9\%) was obtained from the Nanning Air Separation Gas Co., Ltd. (Guangxi, China).

\subsection{Preparation and Purification of XEHR}

\subsubsection{Use High-Pressure $\mathrm{CO}_{2}$ as Catalyst}

The esterification reaction between the hydrogenated rosin and xylitol was catalyzed by high-pressure $\mathrm{CO}_{2}$ in an FYX-2 (Jingyi reaction kettle Co., Ltd., Dalian, China) stainless steel autoclave. The hydrogenated rosin and xylitol were added to the autoclave in the desired proportion, after which the unit was sealed and air was removed using a vacuum pump. After the seal was tested, the reactor was filled with $\mathrm{CO}_{2}$ and evacuated again three times. The reaction was initiated by injecting a specific quantity of $\mathrm{CO}_{2}$ as a gaseous catalyst and heating the reactor. During the reaction process, the exhaust valve was opened once an hour to discharge water vapor and allow the reactor to be refilled with $\mathrm{CO}_{2}$.

Following the reaction, trace unreacted xylitol was possibly retained in the XEHR, which would be expected to induce errors in acid values for the products. To eliminate these effects, $50 \mathrm{~g}$ of the XEHR product was mixed with $80 \mathrm{~g}$ turpentine and $100 \mathrm{~g}$ saturated brine after the reaction, followed by stirring for $30 \mathrm{~min}$ in a $70{ }^{\circ} \mathrm{C}$ water bath. The turpentine phase was subsequently separated and washed three times with distilled water. Finally, the turpentine and residual water were removed by distillation under vacuum to give the final product.

\subsubsection{Use $\mathrm{ZnO}$ as Catalyst}

Hydrogenated rosin and xylitol were added to the autoclave according to the required proportion, $0.8 \% \mathrm{ZnO}$ was added (based on the quality of hydrogenated rosin), and then the device was sealed and the reactor was heated to start the reaction. During the reaction process, the exhaust valve was opened once an hour to discharge water vapor.

The purification steps after the reaction are the same as those in Section 3.2.1. 


\subsubsection{Without Using Any Catalysts}

Hydrogenated rosin and xylitol were added to the autoclave according to the required proportion, and then the device was sealed and the reactor was heated to start the reaction. During the reaction process, the exhaust valve was opened once an hour to discharge water vapor.

The purification steps after the reaction are the same as those in Section 3.2.1.

\subsection{Fundamental Properties of XEHR}

\subsubsection{Determination of Conversion Values}

The acid value was the main parameter used to ascertain the quality of the XEHR, and acid values were converted using the equation:

$$
\text { conversion }(\%)=\left(1-\frac{N_{E}}{N_{R}}\right) * 100 \%
$$

where $N R$ and NE are the acid values of the original hydrogenated rosin and of the XEHR, respectively, both of which could be determined based on the ASTM D-465 standard [51].

\subsubsection{HLB Values}

Hydrophilic-lipophilic balance (HLB) values were determined by accurately weighing $1 \mathrm{~g}$ portions of the XEHR samples into $125 \mathrm{~mL}$ Erlenmeyer flasks and adding $30 \mathrm{~mL}$ of an isopropanol/ benzene (100:15 $v / v)$ mixture to dissolve the samples. Following this, each sample was titrated with double-distilled water until persistent turbidity was obtained. In the method reported by Greenwald et al. [52], the volume of water added is termed the water index. A calibration curve was constructed using span-80 (HLB = 4.3) and tween-80 (HLB = 15.0) mixtures, and intermediate HLB values were calculated using the equation:

$$
\mathrm{HLB}_{\text {mix }}=\frac{w_{A} H L B_{A}+w_{B} H L B_{B}}{w_{A}+w_{B}}, w_{A}+w_{B}=1 g
$$

where $H L B_{A}$ and $H L B_{B}$ are the HLB values obtained for the span-80 and tween-80.

\subsubsection{ICP-AES}

The original hydrogenated rosin, XEHR prepared with high-pressure $\mathrm{CO}_{2}$, and XEHR prepared with $\mathrm{ZnO}$ as a catalyst under the same conditions were analyzed by inductively coupled plasma-atomic emission spectroscopy (ICP-AES) to determine the mass fractions of $\mathrm{Cu}, \mathrm{Fe}, \mathrm{Zn}, \mathrm{Pb}$, and $\mathrm{Ni}$ in these materials.

\subsection{Characterization of XEHR}

\subsubsection{Fourier Transform Infrared Spectroscopy}

Prior to analyses by a Shimadzu Iraffinity-1s Fourier transform infrared (FTIR) spectroscopy (Shimadzu, kyoto, Japan), samples of the hydrogenated rosin or XEHR were mixed with KBr powder and pressed into transparent sheets. The main functional groups in these samples were analyzed over the wavenumber range of $4000-400 \mathrm{~cm}^{-1}$.

\subsubsection{NMR}

Analyses by ${ }^{1} \mathrm{H}$ and ${ }^{13} \mathrm{C}$ nuclear magnetic resonance (NMR) spectroscopy were performed with a Bruker ADVANCE III HD600 spectrometer (Bruker, Switzerland). A $40 \mathrm{mg}$ portion of each sample was dissolved in $600 \mathrm{~mL} \mathrm{CDCl}_{3}$, and spectra were acquired at $298 \mathrm{~K}$. All chemical shifts are reported relative to that of tetramethylsilane (TMS). 


\subsubsection{GPC}

Gel permeation chromatography (GPC) analyses were conducted using a Waters 1525 instrument with a refractive index (RI) detector and a Phenogel column (00H-0441-K0). Mobile phase was THF. The samples were diluted in THF at a concentration of $5 \mathrm{mg} / \mathrm{mL}$, and a $1.00 \mathrm{~mL} / \mathrm{min}$ flow rate was employed together with a column temperature of $40^{\circ} \mathrm{C}$.

\subsection{Emulsion Preparation}

\subsubsection{Surface and Interfacial Tensions}

The equilibrium surface tension was determined using the ring method (DCAT21 tensiometer), while the interfacial tension was measured with a JJ2000B spinning droplet tensiometer (POWEREACH, Shanghai, China). During these trials, the vessel containing the solution to be measured was immersed in a constant-temperature water bath held at $25.0 \pm 0.05^{\circ} \mathrm{C}$. The tensiometer was calibrated with double-distilled water. The deviation between replicate surface tension measurements was less than $0.2 \mathrm{mN} / \mathrm{m}$.

\subsubsection{Emulsification Properties}

In emulsification tests, the XEHR was dissolved in soybean oil to form a $2 \%(w / v)$ solution, after which a salt emulsion was prepared by mixing aqueous $\mathrm{NaCl}, \mathrm{KCl}, \mathrm{CaCl}$, or $\mathrm{MgCl}_{2}$ solutions with the soybean oil solution containing the $2 \%$ XEHR so as to obtain a water-to-oil volume ratio of 1:4. Varying $\mathrm{pH}$ values of $4,6.86$, or 10 were prepared by adding $\mathrm{HCl}$ or $\mathrm{NaOH}$ to these mixtures. (Such as for XEHR water in oil emulsion containing $10 \mathrm{mM} \mathrm{NaCl}$, the final $100 \mathrm{~mL}$ emulsion contained $80 \mathrm{~mL}$ soybean oil, $20 \mathrm{~mL}$ water, $1 \mathrm{mmol} \mathrm{NaCl}$, and $1.6 \mathrm{~g}$ XEHR). These mixtures were homogenized twice using an AH-100D high-pressure homogenizer (ATS Engineering, Ltd., Toronto, ON, Canada) at a pressure of 18,000 bar to form water/oil emulsions. The emulsifying activity index (EAI) and emulsifying stability index (ESI) of the emulsions containing the XEHR were determined by the improved turbidimetric method. In this method, aliquots of each emulsion $(100 \mu \mathrm{L})$ were taken from the bottom of the bottle both immediately after preparation of the emulsion and after $10 \mathrm{~min}$, then diluted with $5 \mathrm{~mL}$ of a $0.1 \%$ sodium dodecyl sulfate (SDS) solution [53]. An ultraviolet/visible (UV/vis) spectrophotometer (S2000) was used to determine the absorbance of each diluted emulsion at $500 \mathrm{~nm}$. The EAI and ESI were calculated using the equations:

$$
\begin{gathered}
\text { EAI }\left(\frac{m^{2}}{g}\right)=2 T\left(A_{0} \cdot \frac{\text { dilution }}{C \cdot \theta \cdot 10000}\right) \\
\text { ESI }(\%)=\frac{A_{10}}{A_{O}} * 100
\end{gathered}
$$

where $T$ is $2.303, A_{0}$ is the absorbance at $500 \mathrm{~nm}$ measured immediately after homogenization, "dilution" is $100, C$ is the concentration of XEHR $(\mathrm{g} / \mathrm{mL})$ in the oil phase prior to emulsion formation, $\theta$ is the oil volume fraction in the emulsion, and $A_{10}$ is the absorbance at $500 \mathrm{~nm}$ after $10 \mathrm{~min}$ [46,54].

\subsubsection{Droplet Size Distribution and Zeta Potentials}

A Zetasizer Nano ZS laser nanoparticle size analyzer (Malvern Co., Worcestershire, UK) was used to measure the particle sizes and surface charges in the emulsions at $25^{\circ} \mathrm{C}$. Prior to these measurements, each emulsion was diluted by a factor of 100 using soybean oil. The hydrodynamic diameter and zeta potential of the particles provided herein represent the averages of at least three measurements [11].

\subsubsection{Confocal Laser Scanning Microscopy}

The microstructures of the freshly prepared emulsions were analyzed by confocal laser scanning microscopy (CLSM; Olympus, FV3000, Tokyo, Japan). For this purpose, rhodamine B was added to 
the emulsion according to the ratio of $10 \mu \mathrm{g} / \mathrm{mL}$, and a $0.2 \mathrm{~mL}$ aliquot of the emulsion was obtained and diluted with $1.8 \mathrm{~mL}$ of soybean oil. A small drop of the diluted emulsion was transferred to a glass slide, covered with a slip, and then immediately observed. A $40 \times$ objective lens was used for the surface observations of the emulsion droplets.

\subsubsection{Rheological Behaviors}

Flow curves were recorded for emulsion samples at $25^{\circ} \mathrm{C}$ shear rates in the range of $1-100 \mathrm{~s}^{-1}$, using an NDJ-1F Brookfield rotational viscometer (Shanghai, China) for the determination of viscosity. A concentric cylinder geometry (rotor 21) was used for these measurements.

\section{Conclusions}

The synthesis of XEHR using a "green" high-pressure $\mathrm{CO}_{2}$ system was demonstrated with a 91.51\% yield. The product did not contain heavy metal residues. Employing a soybean oil/water volume ratio of $4: 1$, the XEHR was used to prepare emulsions via high-pressure homogenization. This ester exhibited satisfactory interfacial activity and emulsification performance in both acidic and alkaline environments and in the presence of various salts. The microstructures of the emulsions showed that the presence of salts improved droplet dispersion to generate more stable mixtures. This effect may be related to the adsorption of ions on the surfaces of the emulsion droplets and to the type of ion. This work provides data regarding the physicochemical and emulsifying properties of a new bio-based emulsifier, and it suggests that XEHR may have numerous applications.

Supplementary Materials: The following are available online at http://www.mdpi.com/1420-3049/25/2/302/s1, Figure S1: FT-IR spectra of the XEHR and the hydrogenated rosin; Figure S2: ${ }^{1} \mathrm{H}$ and ${ }^{13} \mathrm{C}$ NMR spectra obtained from the XEHR.

Author Contributions: H.Q. performed the majority of the experiments, analyzed the data, and drafted the paper; X.C. conceived and designed the experiments; X.W. and J.L. contributed reagents/materials/analysis tools; D.Z. contributed with the analysis of the data; L.W. conceived and designed the study, supervised the experiment work, and reviewed and edited the manuscript. All authors have read and agreed to the published version of the manuscript.

Funding: This work was supported by the National Natural Science Foundation of China (grant no. 21878056) and (grant no. 31560241), the Guangxi Natural Science Foundation (grant no. 2014GXNSFDA118010), Key Laboratory of Petrochemical Resource Processing and Process Intensification Technology (grant no. 2019Z02), and the Project for Cultivating New Century Academic and Technology Leaders of Nanning City (No. 2018013).

Conflicts of Interest: The authors declare no competing interests.

\section{References}

1. Hay, W.T.; Fanta, G.F.; Felker, F.C.; Peterson, S.C.; Skory, C.D.; Hojilla-Evangelista, M.P.; Biresaw, G.; Selling, G.W. Emulsification properties of amylose-fatty sodium salt inclusion complexes. Food Hydrocoll. 2019, 90, 490-499. [CrossRef]

2. Koliastasi, A.; Kompothekra, V.; Giotis, C.; Moustakas, A.K.; Skotti, E.P.; Gerakis, A.; Kalogianni, E.P.; Georgiou, D.; Ritzoulis, C. Novel emulsifiers from olive mill compost. Food Hydrocoll. 2020, 99, 105373. [CrossRef]

3. Gaur, V.K.; Regar, R.K.; Dhiman, N.; Gautam, K.; Srivastava, J.K.; Patnaik, S.; Kamthan, M.; Manickam, N. Biosynthesis and characterization of sophorolipid biosurfactant by Candida spp.: Application as food emulsifier and antibacterial agent. Bioresour. Technol. 2019, 285, 121314. [CrossRef] [PubMed]

4. Duprat-de-Paule, S.; Guilbot, J.; Roso, A.; Cambos, S.; Pierre, A. Augmented bio-based lipids for cosmetics. OCL 2018, 25, D503. [CrossRef]

5. Zhang, M.; Wei, L.; Chen, H.; Du, Z.; Binks, B.P.; Yang, H. Compartmentalized droplets for continuous flow Liquid-Liquid interface catalysis. J. Am. Chem. Soc. 2016, 138, 10173-10183. [CrossRef]

6. Zhang, L.; Zhang, X.; Zhang, P.; Zhang, Z.; Liu, S.; Han, B. Efficient emulsifying properties of glycerol-based surfactant. Colloids Surf. A: Physicochem. Eng. Asp. 2018, 553, 225-229. [CrossRef] 
7. Nakauma, M.; Funami, T.; Noda, S.; Ishihara, S.; Al-Assaf, S.; Nishinari, K.; Phillips, G.O. Comparison of sugar beet pectin, soybean soluble polysaccharide, and gum arabic as food emulsifiers. 1. Effect of concentration, $\mathrm{pH}$, and salts on the emulsifying properties. Food Hydrocoll. 2008, 22, 1254-1267.

8. Hosseini-Parvar, S.H.; Osano, J.P.; Matia-Merino, L. Emulsifying properties of basil seed gum: Effect of $\mathrm{pH}$ and ionic strength. Food Hydrocoll. 2016, 52, 838-847. [CrossRef]

9. Habulin, M.; Šabeder, S.; Knez, Ž. Enzymatic synthesis of sugar fatty acid esters in organic solvent and in supercritical carbon dioxide and their antimicrobial activity. J. Supercrit. Fluids 2008, 45, 338-345. [CrossRef]

10. Acevedo-Fani, A.; Soliva-Fortuny, R.; Martín-Belloso, O. Nanostructured emulsions and nanolaminates for delivery of active ingredients: Improving food safety and functionality. Trends Food Sci. Tech. 2017, 60, 12-22. [CrossRef]

11. Tang, S.; Yu, J.; Lu, L.; Fu, X.; Cai, Z. Interfacial and enhanced emulsifying behavior of phosphorylated ovalbumin. Int. J. Biol. Macromol. 2019, 131, 293-300. [CrossRef] [PubMed]

12. Burger, T.G.; Zhang, Y. Recent progress in the utilization of pea protein as an emulsifier for food applications. Trends Food Sci. Tech. 2019, 86, 25-33. [CrossRef]

13. Agyare, K.K.; Addo, K.; Xiong, Y.L. Emulsifying and foaming properties of transglutaminase-treated wheat gluten hydrolysate as influenced by $\mathrm{pH}$, temperature and salt. Food Hydrocoll. 2009, 23, 72-81. [CrossRef]

14. Fink, J.K. Reactive Polymers: Fundamentals and Applications: A Concise Guide to Industrial Polymers; William Andrew: Norwich, NY, USA, 2017.

15. Wang, J.; Lu, C.; Liu, Y.; Wang, C.; Chu, F. Preparation and characterization of natural rosin stabilized nanoparticles via miniemulsion polymerization and their pressure-sensitive adhesive applications. Ind. Crop. Prod. 2018, 124, 244-253. [CrossRef]

16. Karlberg, A.T.; Boman, A.; Nilsson, J.L.G. Hydrogenation reduces the allergenicity of colophony (rosin). Contact Dermat. 1988, 19, 22-29. [CrossRef]

17. Huang, Z.; Wei, X.J.; Chen, X.P.; Zheng, Q. Microwave-assisted synthesis of hydrogenated rosin-based quaternary ammonium surfactant and its properties. Chem. Ind. For. Prod. 2012, 32, 41-45.

18. Jia, W.; Rao, X.; Song, Z.; Shang, S. Microwave-assisted synthesis and properties of a novel cationic gemini surfactant with the hydrophenanthrene structure. J. Surfactants Deterg. 2009, 12, 261-267. [CrossRef]

19. Kugler, S.; Ossowicz, P.; Malarczyk-Matusiak, K.; Wierzbicka, E. Advances in Rosin-Based chemicals: The latest recipes, applications and future trends. Molecules 2019, 24, 1651. [CrossRef]

20. Code of Federal Regulations; US Food and Drug Administration: Silver Spring, MD, USA, 2012.

21. El Ministerio de Sanidad, Política Social e Igualdad Publica el Primer Documento de Análisis de Situación de las Terapias Naturales; Ministerio de Sanidad, Política Social e Igualdad: Madrid, Spain, 2011.

22. Leitner, W. Supercritical carbon dioxide as a green reaction medium for catalysis. Acc. Chem. Res. 2002, 35, 746-756. [CrossRef]

23. Albuquerque, T.L.D.; Da Silva, I.J.; de Macedo, G.R.; Rocha, M.V.P. Biotechnological production of xylitol from lignocellulosic wastes: A review. Process. Biochem. 2014, 49, 1779-1789. [CrossRef]

24. Zhang, X.; Nie, K.; Wang, M.; Liu, L.; Li, K.; Wang, F.; Tan, T.; Deng, L. Site-specific xylitol dicaprate ester synthesized by lipase from Candida sp. 99-125 with solvent-free system. J. Mol. Catal. B: Enzym. 2013, 89, 61-66. [CrossRef]

25. Brunzell, J.D. Use of fructose, xylitol, or sorbitol as a sweetener in diabetes mellitus. Diabetes Care 1978, 1, 223-230. [CrossRef] [PubMed]

26. Ly, K.A.; Milgrom, P.; Rothen, M. Xylitol, sweeteners, and dental caries. Pediatric Dent. 2006, 28, $154-163$.

27. Piao, J.; Kishi, S.; Adachi, S. Surface tensions of aqueous solutions of 1- O-monoacyl sugar alcohols. Colloids Surf. A: Physicochem. Eng. Asp. 2006, 277, 15-19. [CrossRef]

28. Ferrer, M.; Soliveri, J.; Plou, F.J.; López-Cortés, N.; Reyes-Duarte, D.; Christensen, M.; Copa-Patiño, J.L.; Ballesteros, A. Synthesis of sugar esters in solvent mixtures by lipases from Thermomyces lanuginosus and Candida antarctica B, and their antimicrobial properties. Enzym. Microb. Tech. 2005, 36, 391-398. [CrossRef]

29. Food Additives Permitted for Direct Addition to Food for Human Consumption; Code of Federal Regulations; Food and Drug Administration, US Department of Health and Human Services: Silver Spring, MD, USA, 2016.

30. Gadhave, A. Determination of hydrophilic-lipophilic balance value. Int. J. Sci. Res. 2014, 3, 573-575.

31. Hemmings, P.N.; Wang, L. Rosin Ester Derivative as Surfactants. U.S. Patent No. 5,552,519, 3 September 1996.

32. Dhanorkar, V.T.; Gawande, R.S.; Gogte, B.B.; Dorle, A.K. Development and characterization of rosin-based polymer and its application as a cream base. J. Cosmet. Sci. 2002, 53, 199-208. 
33. Atta, A.M.; Ramadan, A.M.; Shaffei, K.A.; Nassar, A.M.; Ahmed, N.S.; Fekry, M. Synthesis and properties of nonionic surfactants from rosin-imides maleic anhydride adduct. J. Dispers. Sci. Technol. 2009, 30, 1100-1110. [CrossRef]

34. Pa, D.; Gogte, B.B. Synthesized and chacterisation polymeric materials based on coconut oil, rosin \& maleic anhydrides. Int. J. Knowl. Eng. 2012, 1,77-79.

35. Xu, Z.; Lou, W.; Zhao, G.; Zhang, M.; Hao, J.; Wang, X. Pentaerythritol rosin ester as an environmentally friendly multifunctional additive in vegetable oil-based lubricant. Tribol. Int. 2019, 135, 213-218. [CrossRef]

36. Biçer, A.; Sarı, A. Synthesis and thermal energy storage properties of xylitol pentastearate and xylitol pentapalmitate as novel solid-liquid PCMs. Sol. Energ. Mat. Sol. C. 2012, 102, 125-130. [CrossRef]

37. Cramer, J.F.; Dueholm, M.S.; Nielsen, S.B.; Pedersen, D.S.; Wimmer, R.; Pedersen, L.H. Controlling the degree of esterification in lipase catalysed synthesis of xylitol fatty acid esters. Enzym. Microb. Tech. 2007, 41, 346-352. [CrossRef]

38. Albarrán-Preza, E.; Corona-Becerril, D.; Vigueras-Santiago, E.; Hernández-López, S. Sweet polymers: Synthesis and characterization of xylitol-based epoxidized linseed oil resins. Eur. Polym. J. 2016, 75, 539-551. [CrossRef]

39. Sinzato, Y.Z.; Sousa Dias, N.J.; Cunha, F.R. An experimental investigation of the interfacial tension between liquid-liquid mixtures in the presence of surfactants. Exp. Therm. Fluid Sci. 2017, 85, 370-378. [CrossRef]

40. Guo, L.; Li, Q.; Jin, X. Synthesis and surface activities of organic solvent-soluble fluorinated surfactants. J. Fluor. Chem. 2009, 130, 674-681.

41. Yang, X.; Nisar, T.; Hou, Y.; Gou, X.; Sun, L.; Guo, Y. Pomegranate peel pectin can be used as an effective emulsifier. Food Hydrocoll. 2018, 85, 30-38. [CrossRef]

42. Zhang, Q.; Cai, B.; Xu, W.; Gang, H.; Liu, J.; Yang, S.; Mu, B. Novel zwitterionic surfactant derived from castor oil and its performance evaluation for oil recovery. Colloids Surf. A: Physicochem. Eng. Asp. 2015, 483, 87-95. [CrossRef]

43. Kakati, A.; Sangwai, J.S. Effect of monovalent and divalent salts on the interfacial tension of pure hydrocarbon-brine systems relevant for low salinity water flooding. J. Petrol. Sci. Eng. 2017, 157, 1106-1114. [CrossRef]

44. Tokle, T.; McClements, D.J. Physicochemical properties of lactoferrin stabilized oil-in-water emulsions: Effects of pH, salt and heating. Food Hydrocoll. 2011, 25, 976-982. [CrossRef]

45. Liu, X.; Ji, L.; Zhang, T.; Xue, Y.; Xue, C. Effects of pre-emulsification by three food-grade emulsifiers on the properties of emulsified surimi sausage. J. Food Eng. 2019, 247, 30-37. [CrossRef]

46. Chen, Y.; Jiang, S.; Chen, Q.; Liu, Q.; Kong, B. Antioxidant activities and emulsifying properties of porcine plasma protein hydrolysates modified by oxidized tannic acid and oxidized chlorogenic acid. Process. Biochem. 2019, 79, 105-113. [CrossRef]

47. Zhang, Y.; Zhou, X.; Zhong, J.; Tan, L.; Liu, C. Effect of pH on emulsification performance of a new functional protein from jackfruit seeds. Food Hydrocoll. 2019, 93, 325-334. [CrossRef]

48. Cabezas, D.M.; Ortiz, M.P.; Wagner, J.R.; Porfiri, M.C. Effect of salt content and type on emulsifying properties of hull soy soluble polysaccharides at acidic pH. Food Res. Int. 2017, 97, 62-70. [CrossRef]

49. Joshi, M.; Adhikari, B.; Aldred, P.; Panozzo, J.F.; Kasapis, S.; Barrow, C.J. Interfacial and emulsifying properties of lentil protein isolate. Food Chem. 2012, 134, 1343-1353. [CrossRef] [PubMed]

50. Liu, Y.; Hu, X.; Ye, Y.; Wang, M.; Wang, J. Emulsifying properties of wheat germ: Influence of $\mathrm{pH}$ and $\mathrm{NaCl}$. Food Hydrocoll. 2020, 100, 105431. [CrossRef]

51. Ladero, M.; de Gracia, M.; Tamayo, J.J.; Ahumada, I.L.D.; Trujillo, F.; Garcia-Ochoa, F. Kinetic modelling of the esterification of rosin and glycerol: Application to industrial operation. Chem. Eng. J. 2011, 169, 319-328. [CrossRef]

52. Shi, Y.; Yan, F.; Jia, Q.; Wang, Q. Norm descriptors for predicting the hydrophile-lipophile balance (HLB) and critical micelle concentration (CMC) of anionic surfactants. Colloids Surf. A: Physicochem. Eng. Asp. 2019, 583, 123967. [CrossRef]

53. Mozafarpour, R.; Koocheki, A.; Milani, E.; Varidi, M. Extruded soy protein as a novel emulsifier: Structure, interfacial activity and emulsifying property. Food Hydrocoll. 2019, 93, 361-373. [CrossRef] 
54. Cha, Y.; Wu, F.; Zou, H.; Shi, X.; Zhao, Y.; Bao, J.; Du, M.; Yu, C. High-Pressure homogenization Pre-Treatment improved functional properties of oyster protein isolate hydrolysates. Molecules 2018, 23, 3344. [CrossRef] [PubMed]

Sample Availability: Samples of the compounds are available to qualified researchers from the authors.

(C) 2020 by the authors. Licensee MDPI, Basel, Switzerland. This article is an open access article distributed under the terms and conditions of the Creative Commons Attribution (CC BY) license (http://creativecommons.org/licenses/by/4.0/). 